ఠ

\title{
Nalmefene and alcohol dependence: a new approach or the same old unacceptable marketing?
}

LETTER

\author{
Alain Braillon ${ }^{1, *}$ \\ Bernard Granger ${ }^{2, *}$ \\ 'Alcohol Treatment Unit, University \\ Hospital, Amiens, France; '2Psychiatry, \\ Tarnier Hospital (AP-HP), Paris, \\ France \\ *Both authors contributed equally \\ to this work
}

This article was published in the following Dove Press journal:

Substance Abuse and Rehabilitation

29 June 2015

Number of times this article has been viewed

\section{Dear editor}

"A great deal of intelligence can be invested in ignorance when the need for illusion is deep". Saul Bellow

Paille and Martini's review on nalmefene for alcohol dependence deserves some comment. ${ }^{1}$

First, the authors stated no conflict of interest despite both repeatedly received money from Lundbeck laboratories, the company marketing nalmefene (eg, http:// www.lundbeck.com/fr/a-propos-de-lundbeck/transparence-des-liens and https://www. transparence.sante.gouv.fr/flow/main?execution=e2s1). We recently challenged such unprofessional behavior in a French journal where authors also masked their conflicts of interest and provided an inaccurate analysis. ${ }^{2}$

Second, the data analysis is flawed and failed to discuss the limitations.

a. Nalmefene [17-N-cyclopropylmethyl-3,14-dihydroxy-4,5-beta-alpha-epoxy-6 methylenemorphinan hydrochloride $(10365 \mathrm{NIH})]$, is a simple 6-methyl derivative of naltrexone. Its origin goes back to early 1980. Naltrexone is a drug that had a marketing authorization on validated and rigorous criteria (abstinence) and all the related numerous independent trials using a solid methodology are consistent. ${ }^{3,4}$ Instead, nalmefene is characterized by a dystocia. In 1998, Contral Pharma tried to develop nalmefene against alcohol use disorders. The trials in this indication like in other more anecdotal conditions (eating behavior, memory disorder, bronchospasm, pruritus, cystitis ...) have been unsuccessful, the results failing to reach statistical significance. The Lundbeck laboratory acquired the patent for this somewhat forgotten molecule and tried to relaunch its development.

b. "If you torture the data enough, nature will Always confess". Ronald Coase. All three trials (Sense 1,2 and 3) exhibit poor results, which may explain why these have not been published in the core clinical journals unlike the pivotal trials of acamprosate or naltrexone. ${ }^{4-6}$ Sense 1 and 2 trials were pooled to provide a basis for the marketing authorization with a post hoc analysis of a subgroup of patients - representing only $1 / 4$ of the cohort, this is far from an intention to treat analysis. ${ }^{7.8}$ There were too many missing data and too many patients were lost to follow-up. ${ }^{9}$ Sense 3 study is not significant regarding the 4 endpoint measures (both primary and secondary). ${ }^{10}$ But the authors underlined significant results for endpoints at the 13th month despite this was not in the original protocol of the study. Last, there is a significant bias of
Correspondence: Alain Braillon Alcohol Treatment Unit, University Hospital, Amiens, France

Email braillon.alain@gmail.com 
attrition, only $61 \%$ of patients in the nalmefene group completing the study against $67 \%$ in the placebo group.

c. The endpoint (consumption of alcohol) was on a declarative basis and no objective measures commonly used in the tests were retained: alcohol, CDT (carbohydrate deficient transferrin) or ethyl glucuronide (hair or urine). ${ }^{11}$

d. The endpoint was not validated. The decrease in consumption is a surrogate endpoint and so far no study has shown it could reduce hospitalization, morbidity, or mortality rates. A decrease in consumption could be a temporary solution to develop the therapeutic alliance when a patient is not ready for abstinence. However, considering this endpoint as a success is nothing but hype or a hoax. The paradigm of reducing risks is well established for the risk of infection with a drug addict. Reducing risk by reducing consumption remains a myth. It goes back to 1973, but the extended follow-up of the cohort has shown that this concept was inappropriate. ${ }^{12}$ All studies testing a decrease in consumption failed to show evidence for effectiveness. ${ }^{13}$ What would we say if a drug against morbid obesity had a marketing authorization without data on weight or morbidity because it allows patients to refrain from eating one slice of pizza per day? ${ }^{14}$ The marketing authorization from the European Medicines Agency relied on a "white paper" on accepting the decrease in consumption as a surrogate endpoint. This position is not accepted by the FDA. The "white paper" was authored by van den Brink who has received fees from Lundbeck, as all investigators publishing nalmefene trials. ${ }^{7,8,10}$ Sense 3 was also published in a journal where the two publishers were also paid by Lundbeck and failed to respond to a request to publish a brief critical analysis of the trial (A Braillon, personal communication, 2015). ${ }^{10}$

e. It was neither scientific nor ethical not to compare nalmefene to a validated treatment that received a marketing authorization. Helsinki declaration (1964) stated that any experimental maneuver was to be compared to the best available care as a comparator (Article II.2). It was possible to build such comparative tests.

Third, independent evaluations are negative.

a. The independent drug bulletin Prescrire concluded: "In both trials, patients taking nalmefene declared two "heavy drinking days" per month less than patients in the placebo groups. Daily consumption of alcohol was 5-9 grams lower with nalmefene than with placebo. The most common side effects are insomnia, dizziness, headache and nausea, which were severe in more than $10 \%$ of patients. Other serious but less common side effects include confusion, hallucination and dissociation, usually at the beginning of the treatment. These side effects have affected about $3 \%$ of patients treated with nalmefene, a figure three times higher than in the placebo groups. The consequences of nalmefene mixed with large amounts of alcohol are not known. In practice, the clinical relevance of nalmefene in alcohol-dependent patients seeking to reduce or abstain is questionable. The impact of nalmefene on alcohol dependence complications is not known. The crucial first step in the management of alcohol-dependent patients is to establish a relationship based on trust and to provide psychological and social support. When drugs are considered, it is best to choose acamprosate or naltrexone, drugs that are only moderately effective but better evaluated". ${ }^{15}$

b. The Drug Evaluation German Agency (IQWIG) made its conclusion on December 1: "Nalmefene for alcohol dependence: no benefit evidenced" (https://www.iqwig. de/en/press/press-releases/press-releases/nalmefenefor-alcohol-dependence-added-benefit-not-proven.6458. $\underline{\text { html)}}$.

c. The French Health Authority concluded that nalmefene trials showed little evidence for an improvement in actual benefit when compared to existing treatments (rating $=4$, on a scale of 5 to 1 , the highest). The agency advised to restrict prescription to addiction specialists considering the major importance of psycho-social care, a difficult condition to achieve in general practice. Such restriction is rarely used by the Commission (http://www.has-sante. fr/portail/jcms/c_1737894/en/selincroenct12915englishversion).

d. The Swedish Agency for health assessment concluded (March 31, 2015) to the lack of interest of nalmefene compared to existing treatments and did not recommend its reimbursement (http://www.tlv.se/beslut/beslutlakemedel/avslag-uteslutningar/Selincro-ingar-inte-ihogkostnadsskyddet/).

Fourth, who will benefit from nalmefene? Monthly cost for nalmefene in France is $€ 101.34$ vs $€ 36.07$ for naltrexone. The psychosocial support, a key element in the care of patients with addiction but it is not reimbursed by the health care scheme. Accordingly, this money could have been better used to cover two monthly psychologist visits.

Fifth, on June 19, 2013, the European Commission imposed a $€ 93.8$ million fine to Lundbeck for having offered payments and other bribes to other companies who accepted to delay the marketing of their cheaper generic of citalopram. The Vice-President of the Commission Joaquín Almunia 
said: "Agreements of this type (breach of EU antitrust rules. Article 101 of the Treaty on the Functioning of the European Union) directly affect patients and national health systems, which are already subject to strict budget constraints" (http:// www.europeanvoice.com/article/almunia-fines-lundbeckand-rivals-for-fudging-competition-on-medicines/).

\section{Disclosure}

AB was co-investigator for the clinical trial ALPADIR (baclofen). BG has no conflict of interest related to this communication.

\section{References}

1. Paille F, Martini H. Nalmefene: a new approach to the treatment of alcohol dependence. Subst Abuse Rehabil. 2014;5:87-94.

2. Braillon A, Granger B. [Who can really benefit from nalmefene? Conclusions from independent evaluations]. Encephale. In press 2015.

3. France CP, Gerak LR. Behavioral effects of 6-methylene naltrexone (nalmefene) in rhesus monkeys. J Pharmacol Exp Ther. 1994;270(3): 992-999.

4. Garbutt JC, Kranzler HR, O’Malley SS, et al; Vivitrex Study Group. Efficacy and tolerability of long-acting injectable naltrexonefor alcohol dependence: a randomized controlled trial. JAMA. 2005;293(13): $1617-1625$.

5. Jonas DE, Amick HR, et al. Pharmacotherapy for adults with alcohol use disorders in outpatient settings: a systematic review and meta-analysis. JAMA. 2014;311(18):1889-1900.
6. Lhuintre JP, Daoust M, Moore ND, et al. Ability of calcium bis acetyl Homotaurine, a GABA agonist, to prevent prevention relapse in alcoholics Weaned. Lancet. 1985;1(8436):1014-1016.

7. Van den Brink W, Aubin HJ, Bladström A, Torup L, Gual A, Mann K. Efficacy of as-needed nalmefene in alcohol-dependent patients with at least a high risk drinking level: results from a subgroup analysis of two randomized controlled 6-month studies. Alcohol Alcohol. 2013;48: 570-578.

8. Gual A, He Y, Torup L, van den Brink W, Mann K. ESENSE 2 Study Group. A randomised, double-blind, placebo-controlled, efficacy study of nalmefene, as-needed use, in patients with alcohol dependence. Eur Neuropsychopharmacol. 2013;23:1432-1442.

9. Braillon A. Nalmefene in alcohol misuse:junk assessment by the European Medicines Agency. BMJ. 2014;348:g2017.

10. Van den Brink W, Sørensen P, Torup L, Mann K, Gual A; SENSE for the Study Group. Long-term efficacy, safety and tolerability of nalmefene as-needed in patients with alcohol dependence: A 1-year, randomized controlled study. J Psychopharmacol. 2014;28:733-744.

11. Wurst FM, Kempter C. Seidl S, Alt A. Ethyl glucuronide - a marker ofalcoholconsumption and a relapse marker with clinical and forensic implications. Alcohol Alcohol. 1999;34 (1):71-7.

12. Pendery ML, Maltzman IM, West LJ. Controlled drinking by alcoholics? New Findings and a reassessment of a major affirmative study. Science. 1982;217(4555):169-175.

13. Muckle W, Muckle J, Welch V, Tugwell P. Managed alcohol as a harm reduction response for alcohol addiction in populations at high risk for substance abuse. Cochrane Database Syst Rev. 12 (2012), CD006747.

14. Spence D. Bad medicine: nalmefene in alcohol misuse. BMJ 2014;348:g1531.

15. Prescire. Nalmefene. Alcohol dependence: no advance. Prescrire Int. 2014;23(150):150-152. 


\section{Authors' reply}

\section{François Paille \\ Hervé Martini}

Department of Addiction Treatment, University Hospital, Vandoeuvre-lès-Nancy, France

Correspondence: F Paille

Service d'Addictologie, bâtiment P Canton, CHU de Nancy-Brabois, Allée du Morvan, F-54500 Vandoeuvre-lès-Nancy, France

Email secretariat.pr.paille@chu-nancy.fr

We would like to thank A Braillon and G Granger for their comments and we would like to reply to some of them.

First of all, we declared our conflicts of interest at the time of submission, before publication of the article in the disclosure form designed for this purpose in line with the publisher's procedures. Unfortunately, this declaration was not included in the final version of the article. An amendment has now been published.

\section{The methodological quality of the SENSE and ESENSE I and 2 trials}

In reply to the comment concerning the comparator, the best way to confirm the pharmacological efficacy of a drug is to compare it to a placebo. However, such an approach may not be ethical when a highly effective reference drug is already available. In the context of alcoholism, both the FDA and the EMA recommend that the superiority of the test substance should first be demonstrated versus placebo, in view of the limited efficacy of the available treatments. ${ }^{1,2}$ Furthermore, in the context of a study on nalmefene, no drug has currently been approved for reduction of alcohol consumption and no drug can therefore be considered to be a reference comparator.

Further trials are obviously necessary to determine the position of this new drug with respect to older drugs in order to more clearly define the improvement of the medical service provided by nalmefene.

The discussion concerning the endpoint (alcohol consumption) is interesting. Heavy drinking is a risk factor for various diseases, premature mortality, functional disorders and impaired quality of life. We agree that alcohol consumption is a surrogate endpoint, as the definitive endpoints are the effect on mortality, morbidity, and quality of life. However, studies based on these endpoints are long, difficult to conduct and expensive, which is why the FDA and the EMA accept that new drug trials do not need to be based on these endpoints, but they should show modifications in drinking behavior ascribed to a particular treatment that are likely to translate to improvement in the physical and psychosocial consequences. ${ }^{1,2}$

What is the best way of measuring modifications of alcohol consumption? Everyone knows that patient self-reporting may minimize drinking compared to their real consumption, especially when alcohol abuse and alcohol-related problems are more severe, when the patient has already received a number of treatments or in the presence of cognitive disorders. Nevertheless, patient self-assessment of alcohol consumption by means of the TLFB is "a state-of-the art", validated and recognized procedure, providing a reasonable estimate that is sensitive to change. ${ }^{2-4}$

The use of biomarkers may be helpful, but they are unable to quantify alcohol consumption. They are useful as secondary outcome variables to complete monitoring of treatment effects. Table 1 shows the results of biomarkers in the pooled target population of the ESENSE 1 and 2 trials, confirming objective improvement of liver function tests. $^{5}$

Many studies in the field of alcoholism report high patient drop-out rates, often about $30 \%$ or even $40 \%$ at 6 months to 1 year, hence the importance of intention-to-treat analysis, as performed in the SENSE trials.

It is then useful to investigate by subgroup analyses, clearly identified as secondary analyses, whether there are any patient profiles with a better response to treatment than others, not in order to improve the results of the trial, but with the practical objective of optimizing use of the drug in routine clinical practice by identifying those patients most likely to benefit from treatment.

Table I Variations of biomarkers. Pooled subpopulation of the ESENSE I and 2 trials with high-risk or very high-risk drinking

\begin{tabular}{llll}
\hline $\begin{array}{l}\text { Efficacy } \\
\text { variables }\end{array}$ & $\begin{array}{l}\text { Placebo } \\
\text { Geometric } \\
\text { mean }\end{array}$ & $\begin{array}{l}\text { Nalmefene } \\
\text { Geometric } \\
\text { mean }\end{array}$ & Significance \\
\hline GGT & & 55.8 & \\
Baseline & 57.6 & 43.5 & $P<0.0005$ \\
Week 24 & 53.0 & 29.3 & \\
ALAT & & 26.0 & \\
Baseline & 29.2 & & \\
Week 24 & 30.7 & 31.5 & $P=0.000003$ \\
ASAT & 31.1 & 27.2 & \\
Baseline & 31.2 & & \\
Week 24 & & & \\
\hline
\end{tabular}

Note: Adapted from 5. 


\section{Is reduction of alcohol consumption a relevant endpoint?}

This is a controversial issue and still the subject of heated debate. This issue can be clarified by trying to answer 2 questions:

- Does a reduction of alcohol consumption decrease the harmful effects of alcohol?

Various studies have shown that a reduction of alcohol consumption reduces alcohol-related diseases and mortality. ${ }^{6-8}$

Fillmore showed that heavy drinkers who reduce their consumption (compared to consistent heavy drinkers) improve the likelihood of survival.

Among the 850 patients of the cohort followed for 5 years in the study published by Gual, it is striking to observe that abstinence achieved the best results in terms of all of the various diseases, accidents, hospital admissions, emergency room visits, work, legal and financial problems, while controlled drinking decreased the risks to an intermediate level between abstinent subjects and heavy drinkers. ${ }^{7}$

Rehm recently calculated that, in subjects with a mean initial daily consumption of $91.2 \mathrm{~g}$ of pure alcohol, a difference of consumption of $18.3 \mathrm{~g}$ of pure alcohol per day was associated with a $43 \%$ reduction of mortality. ${ }^{8}$

As the shape of the curve of alcohol harm reduction is exponential, the risk is decreased to a greater extent in subjects with higher initial consumption for a same reduction of alcohol consumption.

These studies also emphasize the importance of reducing or ideally eliminating the number of heavy drinking days. ${ }^{2}$

All these data indicate that abstinence remains the optimal objective for patients with severe alcohol dependence. However, reduction of alcohol consumption, by whatever means, decreases the risk of harm and death. Decreased consumption is therefore a relevant objective for patients with low levels of alcohol dependence, or those who are unable or who do not wish to achieve abstinence.

It should be noted that, for methodological reasons, the meta-analysis by Muckle W highlighted by Braillon was unable to include studies on the efficacy of brief Managed Alcohol Programs on reduction of consumption, which is another issue. ${ }^{10}$

- The key issue is therefore whether some patients can maintain a stable reduction of their drinking over time.

Some patients are able to lastingly reduce their alcohol consumption.
Dawson published, in 2007, the results of wave 2 of the National Epidemiologic Survey on Alcohol and Related Conditions (NESARC) performed 3 years after wave 1 . This study showed that among all patients in complete remission at wave $1,51.0 \%$ of asymptomatic risk drinkers had experienced recurrence of AUD symptoms, compared with $27.2 \%$ of low-risk drinkers and $7.3 \%$ of abstainers. ${ }^{9}$ These results confirm the fact that the most stable objective over time is abstinence, but that a considerable percentage of patients can lastingly maintain decreased consumption, especially when they are low-risk drinkers.

Other studies, especially those derived from the MATCH study, have reported similar results. ${ }^{2}$

For these reasons, the EMA accepts both abstinence and reduction of consumption as endpoints. The FDA, in the new version of its "guidance for industry on developing drug treatments for alcoholism", ${ }^{2}$ has also modified its position and has accepted that drinking patterns other than abstinence can be valid predictors of clinical benefit for patients in drug studies. It proposes as an endpoint, alongside abstinence, the concept of "no heavy drinking".

\section{The clinical and public health relevance of the results}

We believe that psychosocial support is the basis of treatment of patients with alcohol-related disorders, which leaves us with the question of the effect size of treatment by nalmefene. Aubin $\mathrm{HJ}$ recently published complementary analyses on this point. Based on an analysis of the pooled target subpopulation of the ESENSE 1 and 2 trials (641 patients with high-risk or very high-risk drinking), he showed that the number of patients that needed to be treated to obtain one additional responder was low, between 6 and 10 according to the definitions of responders. ${ }^{5}$

At 6 months, nalmefene reduced the number of heavy drinking days by 3.2 days per month and the daily mean consumption of pure alcohol by $14.3 \mathrm{~g}$. As we have previously seen, such a reduction is able to significantly reduce alcohol-related mortality.

Concerning the comparison of effect sizes of treatment with nalmefene, acamprosate and naltrexone, Aubin HJ calculated that the standardised effect sizes for drinking parameters for nalmefene (Cohen's $d=0.33$ for heavy drinking days; 0.36 for total alcohol consumption) were larger than previously reported for acamprosate and naltrexone (effect size - Hedges' g correction on heavy drinking respectively 0.072 and 0.189$){ }^{5,11}$ This comparison must obviously be 
considered with caution, as clinical trials on acamprosate and naltrexone were targeted to achieve abstinence.

Concerning health economic aspects, the NICE, which is not known for being kind to the pharmaceutical industry, requested an independent health economics study that concluded that nalmefene in conjunction with psychosocial support was a cost effective use of NHS resources compared with psychosocial support alone for treating people with alcohol dependence drinking at high risk level (most plausible cost per QALY was likely to be below £5100). ${ }^{12}$

All active drugs have side effects. Those described in the SENSE trials were more common with nalmefene than with placebo, but were usually benign and transient.

Finally, it should be noted that, in France, nalmefene can be prescribed by general practitioners.

\section{Disclosure}

Francois Paille is a consultant for Ethypharm and Lundbeck and has received honoraria from Ethypharm and Lundbeck, speaker fees from Lundbeck and Merck Serono and travel grants from Lundbeck. Hervé Martini has received honoraria from Lundbeck, speaker fees from Lundbeck, and travel grants from Reckitt-Benckiser and Lundbeck.

\section{References}

1. Guideline on the development of medicinal products for the treatment of alcohol dependence. European Medicines Agency, February 18, 2010. EMA/CHMP/EWP/20097/2008. Available from: http://www.ema. europa.eu/docs/en_GB/document_library/Scientific_guideline/2010/03/ WC500074898.pdf. Accessed May 18, 2015.
2. Alcoholism: Developing Drugs for Treatment Guidance for Industry. Food and Drug Administration. February 2015. Available from: http:// www.fda.gov/downloads/drugs/guidancecomplianceregulatoryinform ation/guidances/ucm433618.pdf. Accessed May 18, 2015.

3. Maisto SA, Sobell LC, Cooper AM, Sobell MB. Comparison of two techniques to obtain retrospective reports of drinking behavior from alcohol abusers. Addict Behav. 1982;7:33-38.

4. Babor TF, Steinberg K, Anton R, Del Boca F. Talk is cheap: measuring drinking outcomes in clinical trials. J Stud Alcohol. 2000;61: $55-63$.

5. Aubin HJ, Reimer J, Nutt DJ, et al. Clinical relevance of as-needed treatment with nalmefene in alcohol-dependent patients. Eur Addict Res. 2015;21:160-168.

6. Fillmore KM, Kerr WC, Bostrom A. Changes in drinking status, serious illness and mortality. J Stud Alcohol. 2003;64:278-285.

7. Gual A, Lligoña A, Colom J. Five-year outcome in alcohol dependence. A naturalistic study of 850 patients in Catalonia. Alcohol Alcohol. 1999;34:183-192.

8. Rehm J, Roerecke M. Reduction of drinking in problem drinkers and all-cause mortality. Alcohol Alcohol. 2013;48:509-513.

9. Dawson DA, Goldstein RB, Grant BF. Rates and correlates of relapse among individuals in remission from DSM-IV alcohol dependence: a 3-year follow-up. Alcohol Clin Exp Res. 2007;31:2036-2045.

10. Muckle W, Muckle J, Welch V, Tugwell P. Managed alcohol as a harm reduction intervention for alcohol addiction in populations at high risk for substance abuse. Cochrane Database Syst Rev. 2012;12:CD00674.

11. Maisel NC, Blodgett JC, Wilbourne PL, Humphreys K, Finney JW. Meta-analysis of naltrexone and acamprosate for treating alcohol use disorders: when are these medications most helpful? Addiction. 2013;108:275-293.

12. Stevenson M, Pandor A, Stevens JW, et al. Nalmefene for Reducing Alcohol Consumption in People with Alcohol Dependence: An Evidence Review Group Perspective of a NICE Single Technology Appraisal. Pharmacoeconomics. Epub April 8, 2015.
Substance Abuse and Rehabilitation

\section{Publish your work in this journal}

Substance Abuse and Rehabilitation is an international, peer-reviewed, open access journal publishing original research, case reports, editorials, reviews and commentaries on all areas of addiction and substance abuse and options for treatment and rehabilitation. The manuscript management system is completely online and includes a very quick and fair

\section{Dovepress}

peer-review system. Visit http://www.dovepress.com/testimonials.php to read real quotes from published authors. 